\title{
Corals - the reef and man
}

\author{
from P.K. Swart
}

CORAL reefs have long been recognized as ecosystems of special beauty and diversity. Also, many millions of people depend for their existence on reef systems, particularly in the Indo-Pacific region. The interaction between conservationists and those concerned with the economic importance of coral reefs provided the background for the Fourth International Coral Reef symposium entitled 'The Reef and Man', held in Manila, the Philippines, from 18 to 22 May 1981.

The location of the conference, in the Philippines, marks an awareness of how important reefs are in the economy of this country. The problem to be solved is how man can live in harmony with the reef both maintaining the stability and diversity of the reef environment and providing a livelihood for the surrounding populations.

A major problem facing reefs in many countries is their over-exploitation to provide curios and souvenirs for the Western tourist trade. The Philippines appears to be the largest supplier of coral and shells, exporting mainly to Europe, Japan and America (S.M. Wells, Species Conservation Monitoring Unit). The removal of coral not only destroys the reef but selective cropping of molluscs, such as the Triton, may have a role in the population explosion of coral predators.

There has been much publicity given over the past decade to the problem of Acanthaster planci (the Crown of Thorns starfish) and there is indeed no doubt that certain areas of the Great Barrier Reef are being subjected to renewed infestation. There is controversy over whether the animal is a specialized R-strategist whose population is out of control as a result of some as yet unidentified influence, conceivably brought about by man's activities, or whether the outbreaks are natural cyclical phenomena. A.M. Cameron (University of Queensland) argues that while cyclical outbreaks are common in herbivores, they are undocumented in carnivores. In light of the apparent problems of controlling $A$. planci, outlined by R.A. Kenchington (Great Barrier Reef Marine Park Authority), further research is needed to locate vulnerable areas in its life cycle and to establish whether outbreaks are indeed a cyclical phenomenon.

Perhaps the most confusing aspect of coral reefs is the apparent diversity of coral species. The phenotypic plasticity of corals has caused countless taxonomists to add to the confusion by creating many

P.K. Swart is in the Department of Earth Sciences, University of Cambridge. synonymous species. At last some Australian taxonomists are recognizing the problems which face the non-taxonomist working with corals and eventually a usable key for all genera and species may be developed. A prototype for one of the more complicated genera was presented by C.C. Wallace (James Cook University, Australia).

Two aspects well covered in the conference were reproduction and coral interactions. Both may be important in shaping coral communities, although distinct doubt was cast on the role of coral-coral interactions by R.H. Bradbury (Australian Institute of Marine Sciences). He does not dispute that coral interactions occur, but the analysis of data collected by himself and others showed no evidence of the role of such interactions in shaping coral communities. However, his opinion is not held by everyone, even those working from the same institution.

Data presented on coral reproduction indicated variability in reproductive strategies by both sexual and asexual means. Asexual reproduction by fragmentation appears to be important in some species of Acropora and Porites, and a hitherto unknown method of asexual reproduction, termed 'polyp bale out', has been documented in Stylophora pistillata (P.W. Sammarco, Australian Institute of Marine Sciences). In this latter method, individual polyps appear to abort the original colony, each one forming a new clone.

The most significant phenomenon occurring in coral reefs, calcification, was the most ignored at this conference.

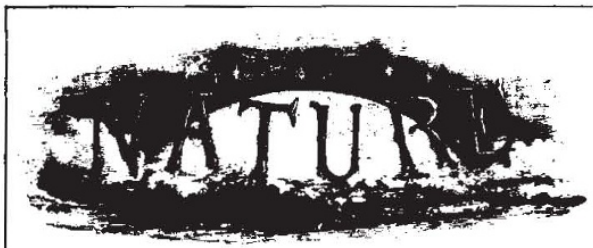

THE BRITISH ASSOCIATION

The Fifty-first Annual Meeting of the British Association was opened yesterday under the presidency of Sir John Lubbock, Bart., M.P,. F.R.S., at York, the birthplace of the Association fifty years ago (September 27, 1831).

Many cities have received the Association twice, but few three times. York will now be one of the latter. The local committee have issued an extremely useful programme of their arrangements, which contains articles on the zoology, botany, and geology of the neighbourhood, and a description of the various excursions. An interesting article on "The York Founders of the Association" is contributed by Archdeacon Hey. An exhibition of art and industrial produce, and a collection of scientific apparatus, will be open during the week. Four excursions are
Despite the passage of over two decades since Goreau proposed a hypothesis for calcification in corals, little progress has been made on the crucial questions of how calcium is transported to the sites of calcification and, even more fundamentally, where these sites are. Similarly the role of the endosymbiotic dinoflagellates is still uncertain. A combined approach is needed to answer these questions as corals are both geological and biological entities, and all too often scientists in one discipline will disregard through ignorance evidence provided by the other science. For example, how are trace elements incorporated into the skeleton and are their concentrations different from inorganic precipitates? Some workers (B.E. Brown, University of Newcastle, and R.E. Dodge, Nova University) have reported that corals from apparently polluted areas have skeletal compositions similar to open oceanic ones, thereby casting doubt on the idea that corals accurately reflect oceanic chemistry.

Since the first Coral Reef Symposium held in Manapam, India, in 1969, the number and interests of reef workers have grown enormously. Consider alone the 290 papers given in four parallel sessions at this symposium as opposed to the 37 at Manapam. This growth of coral reef research has been reflected in the formation of the International Society for Reef Studies whose journal 'Coral Reefs' will appear next year. The coral reef community look forward to the Fifth International Symposium to be held in Tahiti in 1985.

organised for Saturday, September 3: to Scarborough; to Castle Howard; to Helmsley and Rievaulx; and to Brimham Rocks and Harrogate. On the following Thursday there will be seven excursions: to Bolton Abbey and the Strid; to Cleveland; a coast excursion; to Gristhorpe, Speeton, and Scarborough; to Whitby; to Wensleydale; and to Aldborough and Boroughbridge. Among the more important manufactories which will be visited are the telescope works of Messrs. Cooke and Sons, the workshops of the North Eastern Railway, the York glass works, and some extensive confectionery works. Naturalists will be glad to learn that the county possesses a fauna which comprises 513 out of the 717 British Vertebrata, viz. 46 mammals, 307 birds, 12 reptiles, and 148 fishes. It also furnishes 71 per cent of the British flowering-plants and ferns. Geologically the county consists of rounded Chalk Hills, Oolite overlying the Lias, Trias convered with glacial drift and alluvial deposit, and a narrow band of Permian strata. Many opportunities will be afforded to members of studying the geology of the district.

From Nature 24, 401, 1 September, 1881. 